\title{
PRODUÇÃO, PROPRIEDADES E APLICAÇ̃̃O DE CELULASES NA HIDRÓLISE DE RESÍDUOS AGROINDUSTRIAIS
}

\author{
Aline Machado de Castro* \\ Centro de Pesquisas e Desenvolvimento Leopoldo Américo Miguez de Mello, PETRÓLEO BRASILEIRO S.A., Av. Horácio \\ Macedo, 950, Ilha do Fundão, 21941-920 Rio de Janeiro - RJ, Brasil \\ Nei Pereira Jr.
}

Escola de Química, Universidade Federal do Rio de Janeiro, 21945-970 Rio de Janeiro - RJ, Brasil

Recebido em 13/5/09; aceito em 24/6/09; publicado na web em 25/11/09

\begin{abstract}
PRODUCTION, PROPERTIES AND APPLICATION OF CELLULASES IN THE HYDROLYSIS OF AGROINDUSTRIAL RESIDUES. Cellulases have been intensively studied in the past few years, due to the interests in biofuels production from lignocellulosic materials, since they permit maintaining mild conditions during the conversion process. These enzymes can be produced by a broad variety of naturally occurring microorganisms, such as from genera Aspergillus, Trichoderma, Penicillium and Humicola. Targeting the increasing of expression levels, molecular biology tools have been used for heterologous genes insertion in host cells, e. g., Pichia pastoris and Escherichia coli. Enzymes from fungal cellulolytic complex usually act best at pH between 4 and 5 under temperatures from 40 to $60{ }^{\circ} \mathrm{C}$ and can be used for either sequential (SHF) or simultaneous (SSF) hydrolysis together alcoholic fermentation. In this review, the main raw materials for production of cellulases are identified, as well as the state of art of enzymes' properties, production and main applications.
\end{abstract}

Keywords: cellulases; agroindustrial residues; lignocellulose.

\section{INTRODUÇÃo}

Celulases são enzimas que constituem um complexo capaz de atuar sobre materiais celulósicos, promovendo sua hidrólise. Estas enzimas são biocatalisadores altamente específicos que atuam em sinergia para a liberação de açúcares, dos quais glicose é o que desperta maior interesse industrial, devido à possibilidade de sua conversão em etanol. ${ }^{1,2}$

Estas enzimas começaram a ser estudadas durante a Segunda Guerra Mundial. A deterioração de fardas, barracas, bolsas e demais objetos dos acampamentos, fabricados de algodão, chamou a atenção de soldados das forças armadas norte-americanas, instalados nas ilhas Solomon, no Pacífico Sul. Algumas organizações, como a Quartermaster Corps, juntamente com as forças armadas, montaram laboratórios em busca de explicações e soluções imediatas para esse problema, que incluíam a detecção de organismos agentes das deteriorações, seus mecanismos de ação e métodos de controle. $\mathrm{O}$ grupo de trabalho, constituído por oito pesquisadores e liderado pelo Dr. Elwyn T. Reese, passou a conduzir seus experimentos no laboratório das forças armadas, em Natick, Massachusets, Estados Unidos. Como resultado das pesquisas, uma linhagem, codificada como QM6a, de um fungo filamentoso, identificado posteriormente como Trichoderma viride, foi isolada e a esta foi atribuída a característica de excretar enzimas capazes de degradar celulose. Até 1953, Dr. Reese e seu grupo de trabalho já haviam determinado que enzimas naturais, nomeadas celulases, constituem complexos de diversas moléculas com distintas habilidades na degradação do substrato. Em 1956, Dr. Reese aliou seus conhecimentos aos da Dra. Mary Mandels, que, em conjunto, passaram a trabalhar no laboratório em Natick. A partir de então, o foco das pesquisas deixou de ser a prevenção da hidrólise da celulose e passou a ser o melhoramento da produção das enzimas responsáveis por esse fenômeno, pelo micro-organismo isolado anteriormente. Mandels e Reese publicaram diversos estudos sobre a influência dos principais fatores que afetam a produção dessas

*e-mail: alinebio@petrobras.com.br enzimas e formulações de meio de cultivo ideais para o crescimento de $T$. viride. Mais tarde, selecionaram mutantes de Trichoderma com elevada produtividade volumétrica de expressão de celulases, alcançando já inicialmente $3 \mathrm{UI} \mathrm{L}^{-1} \mathrm{~h}^{-1}$. 3-7

Desde então, cada década foi marcada por significativos avanços em estudos sobre as enzimas do complexo celulolítico. O início do século XXI foi marcado por grandes investimentos na produção de celulases, especialmente focada para sua aplicação na obtenção de etanol combustível. Em 2000, o USDOE (United States Department of Energy) iniciou parcerias para acelerar o desenvolvimento tecnológico e tornar viável economicamente a produção de etanol a partir de resíduos do milho (sabugo, palha e bráctea). O Departamento assinou um acordo com o Laboratório Nacional de Energias Renováveis ( $\mathrm{Na}$ tional Renewable Energy Laboratory - NREL) e as duas empresas líderes mundiais em produção de enzimas, Novozymes e Genencor, com a liberação de um montante de USD 17,1 milhões. A meta inicial de reduzir em 10 vezes o custo efetivo das celulases na produção de etanol foi superada e já em 2004 as empresas haviam anunciado uma redução de 12 vezes no custo das enzimas. ${ }^{8-10}$ Similarmente, a empresa canadense Iogen Corporation, líder mundial na produção de etanol de celulose, recebeu financiamento para o desenvolvimento de tecnologia de produção de etanol a partir de biomassas, desta vez, palhas de trigo, cevada e aveia e talo de milho. Em 2000, o governo do Canadá financiou a construção da então única planta demonstrativa de produção de bioetanol do mundo. Em 2002, o grupo Royal Dutch/Shell investiu CAD 46 milhões na Iogen, passando a ter direito a $22 \%$ das conquistas globais da empresa. Em 2004, foi inaugurada uma planta comercial que custou CAD 300 milhões, visando a produção do novo biocombustível, o EcoEthanol ${ }^{\mathrm{TM}}$. Em 2008, o grupo Shell realizou novos investimentos, passando a possuir $50 \%$ das ações da Iogen. ${ }^{11}$

Enfim, os avanços das pesquisas sobre celulases ocorreram em diversas áreas do conhecimento. Ao longo dos anos, e até os dias de hoje, contribuições científicas vêm sendo geradas continuamente, no que tange ao isolamento de micro-organismos produtores de celulases, ao aumento da expressão de celulases por mutações gênicas, à purificação e caracterização de componentes deste complexo enzimático, ao 
entendimento sobre os mecanismos de ataque à celulose, à clonagem e expressão de genes, à determinação de estruturas tridimensionais das celulases e à demonstração do potencial industrial dessas enzimas. ${ }^{12}$

Posto isso, o objetivo desse artigo de revisão é abordar os principais aspectos tecnológicos da produção e aplicação de enzimas do complexo celulolítico. Inicialmente são discutidas as composições e disponibilidade de biomassas, seguido das propriedades e estado da arte de produção das enzimas. Por fim, são apresentadas as aplicações industriais das celulases, com foco na hidrólise de materiais lignocelulósicos.

\section{MATERIAIS LIGNOCELULÓSICOS: DISPONIBILIDADE E COMPOSIÇÃO}

As matérias-primas lignocelulósicas são as fontes renováveis mais abundantemente encontradas na natureza, sendo compreendidas, majoritariamente, pelos materiais agroindustriais, pelos resíduos urbanos e pelas madeiras de angiospermas e gimnospermas. ${ }^{13}$ Dentre essas, os materiais agroindustriais se destacam pelo caráter de resíduo, conferido por sua obtenção após o processamento de matérias-primas que apresentam maior valor agregado, e pela vocação natural que o Brasil possui para sua geração. Sendo assim, a Figura 1 apresenta séries históricas de geração de materiais lignocelulósicos no Brasil, com as massas representadas em base úmida. $\mathrm{O}$ bagaço de cana-deaçúcar, dentre as biomassas consideradas, é a predominante, com uma geração em 2007 de 147 milhões de toneladas. Igualmente, é notória a quantidade gerada das demais biomassas lignocelulósicas: juntos, no ano de 2007, os materiais apresentados na Figura 1 somaram uma massa gerada no Brasil de 606 milhões de toneladas, das quais cerca de 105 milhões de toneladas correspondem à fração celulósica. ${ }^{14,15}$

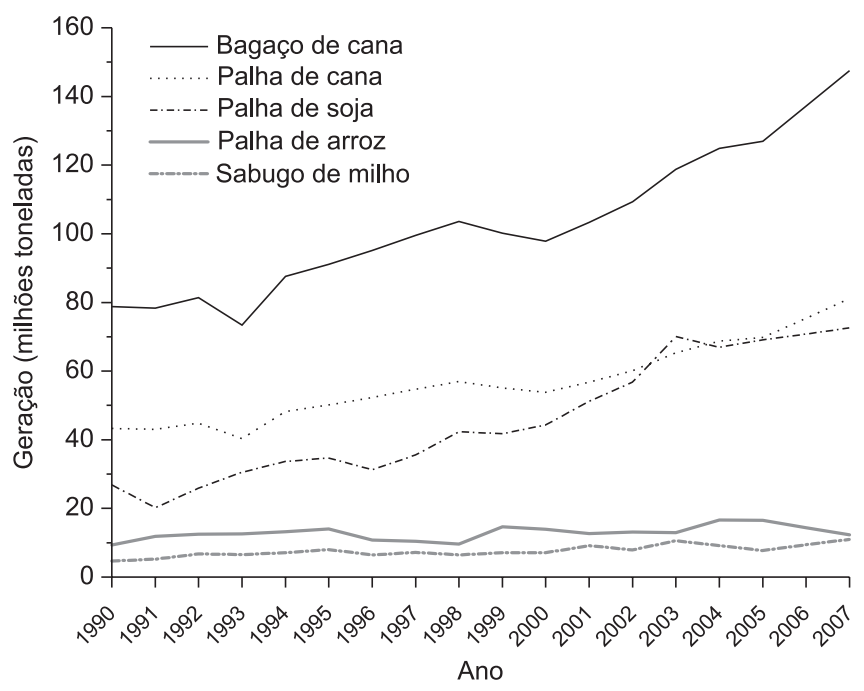

Figura 1. Série histórica de geração de resíduos lignocelulósicos no Brasil ${ }^{14,15}$

As biomassas lignocelulósicas são constituídas por três principais frações poliméricas: lignina, hemicelulose e celulose, que são unidas entre si por ligações covalentes, formando uma rede complexa resistente a ataques microbianos. ${ }^{16}$ Essas frações majoritárias são responsáveis por $97-99 \%$ de toda massa seca dos materiais. Internamente, as fibrilas da fração celulósica, um polissacarídeo composto por glicose (Figura 2), encontram-se dispostas como espirais, de forma a conferir força e flexibilidade ao material. Esta fração encontra-se envolvida pela lignina, polímero aromático heterogêneo formado por ligações éter biologicamente estáveis, ${ }^{17}$ cuja função é aumentar a resistência da estrutura a ataques químicos e enzimáticos. A terceira e última fração principal, a hemicelulose, atua como um elo químico entre a celulose e a lignina, apresentando natureza heteropolissacarídica ramificada, formada, principalmente, por blocos de construção de pentoses (xilose, raminose e arabinose), hexoses (glicose, manose e galactose), ácidos urônicos (ácidos 4-O-metilglucurônico e galacturônico) e radicais acetila. ${ }^{13,18}$ Estas características resultam em materiais flexíveis, porém altamente resistentes a espécies químicas. ${ }^{13}$

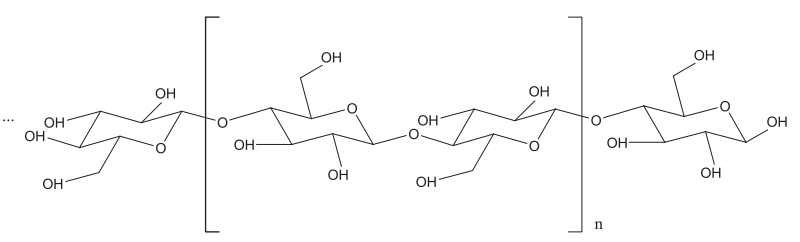

Figura 2. Estrutura da fração celulósica de materiais lignocelulósicos

Assim como a forma e o tamanho da parede celular dos materiais lignocelulósicos variam de espécie para espécie, sua composição química apresenta-se distinta entre representantes lignocelulósicos. De forma geral, a celulose encontra-se em maiores proporções, seguida da hemicelulose e, por fim, da lignina. Mesmo presente em quantidades menores em relação à fração celulósica, a lignina confere limitação suficiente para retardar, ou mesmo impedir completamente, a atuação microbiana sobre o material. A Tabela $1 \mathrm{~S}$, material suplementar, lista a composição de alguns materiais lignocelulósicos, expressa em suas três principais frações.

Dessa forma, faz-se imprescindível o uso de pré-tratamentos no material, com o intuito de aumentar sua susceptibilidade ao agente de interesse, pela remoção da lignina e redução da cristalinidade da estrutura celulósica. ${ }^{19}$ Os pré-tratamentos podem ser classificados em químicos, físicos ou biológicos, e já foram anteriormente descritos nessa mesma publicação. ${ }^{18}$

\section{AS ENZIMAS DO COMPLEXO CELULOLÍTICO}

\section{Classificação e modo de atuação}

As enzimas do complexo celulolítico são hidrolases que clivam ligações $O$-glicosídicas, sendo classificadas pela Enzyme Comission (EC) com a codificação 3.2.1.x, onde o valor de $\mathrm{x}$ varia com a celulase avaliada. ${ }^{20}$

A classificação das celulases, de acordo com seu local de atuação no substrato celulósico, as divide em três grandes grupos: endoglucanases (EnG), que clivam ligações internas da fibra celulósica; exoglucanases (ExG), que atuam na região externa da celulose; e $\beta$-glicosidases (BG), que hidrolisam oligossacarídeos solúveis em glicose. ${ }^{1}$

Endoglucanase, que está classificada com o EC 3.2.1.4, possui como nome sistemático, segundo a IUBMB - International Union of Biochemistry and Molecular Biology, 1,4- $\beta$-D-glucana-4-glucanohidrolase. É a enzima do complexo celulolítico responsável por iniciar a hidrólise. Tal enzima hidrolisa randomicamente as regiões internas da estrutura amorfa da fibra celulósica, liberando oligossacarídeos de diversos graus de polimerização (GP) e, consequentemente, novos terminais, sendo um redutor (quando a glicose possui uma hidroxila heterosídica livre) e um não redutor (quando a hidroxila heterosídica da molécula da extremidade participa de ligação com a glicose adjacente). ${ }^{1} \mathrm{~A}$ EnG é a enzima celulolítica responsável pela rápida solubilização do polímero celulósico (redução do GP), devido à sua fragmentação em oligossacarídeos. ${ }^{21}$

O grupo das exoglucanases $(\mathrm{ExG})$ é constituído por celobiohidrolase $(\mathrm{CBH})$ e glucano-hidrolase $(\mathrm{GH})$. 
A GH (EC 3.2.1.74), cujo nome sistemático é 1,4- $\beta$-D-glucanaglucano-hidrolase, é pouco reportada, mas possui estratégia de hidrólise da fibra celulósica de elevada importância, pois é capaz de liberar glicose diretamente do polímero. ${ }^{1}$

A CBH (EC 3.2.1.91) possui o nome sistemático 1,4- $\beta$-Dglucana-celobio-hidrolase. Embora a IUBMB defina a CBH como catalisadora da hidrólise apenas dos terminais não-redutores da fibra celulósica e oligossacarídeos com GP>3 em celobiose, há relatos do ataque de terminais redutores por essa enzima. ${ }^{1,22} \mathrm{~A} \mathrm{CBH}$ participa da hidrólise primária da fibra e é responsável pela amorfogênese, que é um fenômeno ainda não elucidado completamente, porém sabe-se que envolve uma ruptura física do substrato, acarretando na desestratificação das fibras, pelo aumento das regiões intersticiais. A amorfogênese promove aumentos na taxa de hidrólise da celulose, por tornar amorfas as regiões cristalinas do polímero, deixando-o mais exposto às celulases. ${ }^{23}$

$\mathrm{A} \mathrm{CBH}$ ainda pode ser dividida em dois tipos: enzima do tipo I $(\mathrm{CBH})$, que hidrolisa terminais redutores $(\mathrm{R})$, enquanto que a do tipo II (CBH II) hidrolisa terminais não redutores (NR). Essas enzimas geralmente sofrem inibição pelo seu produto de hidrólise (celobiose). ${ }^{24}$

$\mathrm{O}$ terceiro e último grande grupo de enzimas do complexo celulolítico engloba a $\beta$-glicosidase, ou $\beta$-glicosídeo gluco-hidrolase (EC 3.2.1.21), que é seu nome sistemático. A BG tem a propriedade de hidrolisar celobiose e oligossacarídeos solúveis $(\mathrm{GP}<7)$ em glicose. ${ }^{1,25}$ Assim como a $\mathrm{CBH}$, também é reportada com a característica de sofrer inibição por seu produto de hidrólise. ${ }^{24}$

Quando atuam conjuntamente, as enzimas do complexo celulolítico apresentam um rendimento melhor do que a soma dos rendimentos individuais, ou seja, quando atuam isoladamente umas das outras. Tal efeito é conhecido como sinergia. São conhecidas pelo menos três formas de sinergia entre as celulases: ${ }^{1,12}$ sinergia EnG-ExG - a endoglucanase, atuando nas regiões amorfas da fibra, disponibiliza terminais redutores e não redutores para atuação de $\mathrm{CBH}$ I e $\mathrm{CBH}$ II, respectivamente; sinergia ExG-ExG - as CBH I e CBH II atuam simultaneamente na hidrólise dos terminais redutores e não redutores liberados por ação da endoglucanase; sinergias ExG-BG e EnG-BG - como seus produtos de hidrólise, a celobio-hidrolase e a endoglucanase liberam celobiose e oligossacarídeos, respectivamente, que são substratos para a $\beta$-glicosidase.

A Figura 3 ilustra a ação sinérgica entre exoglucanases, endoglucanase e $\beta$-glicosidase na hidrólise da fibra celulósica.
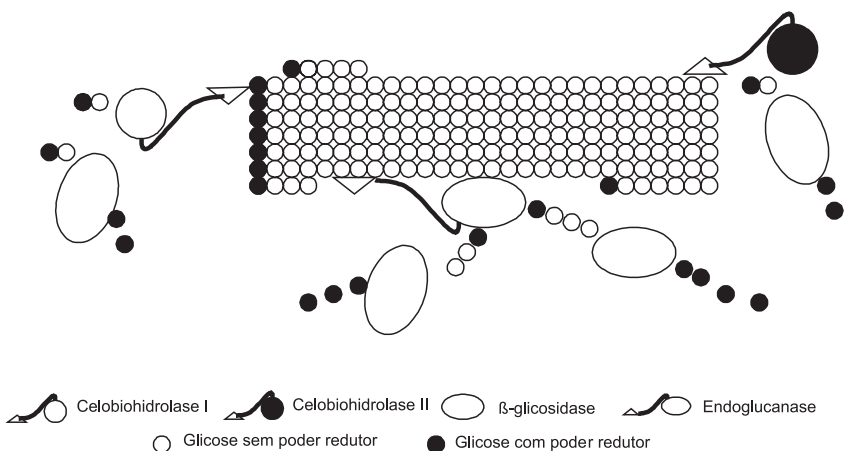

Figura 3. Modo de ação das enzimas do complexo celulolítico

\section{Propriedades}

Com o intuito de se utilizar as celulases em processos industriais sob suas condições de melhor atuação, é imprescindível que suas propriedades sejam determinadas, especialmente no que tange a fatores cinéticos e físico-químicos. Com base nisso, a Tabela $2 \mathrm{~S}$, material suplementar, apresenta valores de algumas propriedades importantes na caracterização de enzimas. De forma geral, as celulases produzidas por fungos filamentosos apresentam valores ótimos de $\mathrm{pH}$ na faixa ácida $(3,6-5,0)$, enquanto que bactérias chegam a produzir celulases altamente ativas em valores de $\mathrm{pH}$ alcalinos. Como exemplo, Zhang e colaboradores também trabalharam com uma linhagem de Bacillus sp., cultivando-a, para a produção de celulases, em pH 10,5. ${ }^{26} \mathrm{Em}$ relação às celulases de actinomicetos (especialmente do gênero Streptomyces), os resultados divulgados indicam que elas possuem melhor atuação em temperaturas por volta de $50{ }^{\circ} \mathrm{C}$ e valores de $\mathrm{pH}$ entre neutros e moderadamente ácidos. ${ }^{27,28} \mathrm{Já}$ as temperaturas ótimas para atuação encontram-se em sua maioria acima de $40^{\circ} \mathrm{C}$.

Em relação a propriedades cinéticas, os valores das constantes $\mathrm{K}_{\mathrm{M}}$ e $\mathrm{V}_{\text {máx }}$ em geral variam em ordem de grandeza, possivelmente devido à heterogeneidade das metodologias de quantificação, à forma de apresentação de seus valores, ao substrato utilizado e, principalmente, à origem do extrato enzimático utilizado. ${ }^{29,30}$ Em que pesem essas diferenças metodológicas, considerações podem ser feitas em relação à importância desses parâmetros. Por exemplo, Anand e Vithayathil compararam o desempenho de uma $\beta$-glicosidase de Humicola lanuginosa sobre dois substratos comumente utilizados para a quantificação de seu poder catalítico: celobiose e p-nitrofenil glicopiranosídeo (pNPG). Pelos valores das constantes de afinidade aos substratos, puderam então tecer comentários relacionados à maior afinidade da enzima sobre o glicídio $\left(\mathrm{K}_{\mathrm{M}}=0,44 \mathrm{mM}\right)$ do que sobre o substrato sintético $\left(\mathrm{K}_{\mathrm{M}}=0,5\right.$ $\mathrm{mM}){ }^{31}$ Yun e colaboradores avaliaram cineticamente o desempenho de uma $\beta$-glicosidase de $T$. harzianum $\mathrm{C}$-4 sobre dez substratos sintéticos derivados de p-nitrofenol. A enzima apresentou maior afinidade sobre p-nitrofenil- $\beta$-gentiobiosídeo $\left(\mathrm{K}_{\mathrm{M}}=0,12 \mathrm{mM}\right)$. No entanto, a taxa máxima de hidrólise $\left(11,0 \mu \mathrm{mol} \mathrm{min}^{-1} \mathrm{mg}^{-1}\right)$ foi bastante inferior à observada sobre pNPG $\left(187 \mu \mathrm{mol} \mathrm{\textrm {min } ^ { - 1 }}\right.$ $\mathrm{mg}^{-1}$ ), substrato para o qual a enzima mostrou ter menor afinidade $\left(\mathrm{K}_{\mathrm{M}}=0,20 \mathrm{mM}\right){ }^{32}$

Por fim, outra propriedade das enzimas celulolíticas comumente reportada na literatura é sua capacidade de ser influenciada por outras moléculas, especialmente metais, seja sofrendo efeitos inibitórios ou indutores. Dentre os íons avaliados, os que inibem mais frequentemente as celulases são $\mathrm{Hg}^{+2}, \mathrm{Cu}^{+2}, \mathrm{Ag}^{+}$e $\mathrm{Zn}^{2+}$, que chegam a provocar até a perda total da atividade catalítica, estando presentes em concentrações tão baixas quanto $2 \mathrm{mM} .^{27,29,33,34}$

\section{Produção}

\section{Estratégias para produção de celulases}

As duas principais estratégias para a produção de celulases por micro-organismos são a fermentação no estado sólido (FES) e a fermentação submersa (FS).

Indubitavelmente, um dos parâmetros mais exaltados na diferenciação desses dois tipos de processos é o teor de água presente no meio reacional. Na FES há ausência ou quase ausência de água livre. ${ }^{35,36} \mathrm{~A}$ água presente nesses sistemas encontra-se complexada com a matriz sólida de substrato ou como uma fina camada absorvida pela superfície das partículas. Em geral, nesses processos o teor de umidade varia entre $30-85 \%$ e a atividade de água típica vai de 0,40-0,90, mimetizando condições encontradas na natureza e permitindo até que sejam conduzidos sem prévia esterilização, visto que a contaminação é pouco provável. ${ }^{37,38}$

A água possui diversas funções em um bioprocesso, tais como, a difusão de nutrientes no meio reacional e a absorção destes pelos agentes microbianos, bem como a remoção de metabólitos; e a manutenção da função e estabilidade de estruturas biológicas, como proteínas, nucleotídeos e carboidratos, da estabilidade da estrutura 
Tabela 1. Comparação das características da fermentação no estado sólido (FES) e da fermentação submersa (FS) ${ }^{37,38,40,41}$

\section{FES}

Menor gama de produtos obtidos e de micro-organismos aptos a crescer nessas condições

Menor possibilidade de contaminação, pela ausência de água livre no sistema

Menor disponibilidade de informações na literatura, no que tange a fenômenos de transporte e cinéticas de crescimento e de produção enzimática

O extrato obtido é em geral de três a quatro vezes menos diluído que na FS, de forma que a produtividade e a concentração final de produto são maiores na FES

Maior dificuldade no controle do processo e na adição de soluções desejadas

Menor volume de resíduos líquidos gerado
FS

Maior demanda energética associada à esterilização do meio e à remoção de produto do meio fermentado

Em que pese a menor concentração de produtos obtida pela FS, a purificação dessas moléculas é facilitada pela ausência ou baixa concentração de partículas de substrato

$\mathrm{O}$ alto teor de água e a natureza diluída do meio facilitam o controle da temperatura de cultivo, reduzindo a degradação do produto, em especial enzimas com baixa termoestabilidade

Quando operando com elevadas concentrações de substrato, podem ocorrer problemas reológicos no sistema

Processos difusionais e de mistura são facilitados devido ao caráter homogêneo do sistema

Tecnologias de monitoramento de variáveis on line mais amplamente disponíveis lamelar e da conservação da permeabilidade da membrana plasmática. Em relação ao cultivo de fungos filamentosos, a limitação de água pode causar a desnaturação de enzimas-chave do metabolismo das células, ocasionando um desequilíbrio nas vias, afetar os processos de germinação, esporulação e formação de metabólitos, assim como reduzir a taxa de crescimento microbiano e aumentar o período de aclimatação celular..$^{37,39}$

Dessa forma, a Tabela 1 lista as principais características da FES e FS. Embora a FS apresente algumas desvantagens em relação à FES, processos envolvendo limitações no teor de água livre no sistema são evitados quando se objetiva a geração de muitos produtos, especialmente em escalas maiores, onde são requeridos biorreatores. $\mathrm{Na}$ última década, diversos autores propuseram geometrias e formas de condução e controle, ${ }^{42-44}$ bem como modelos para descrever os fenômenos envolvidos nesses processos, que, em geral, auxiliam no seu desempenho, mas não contornam completamente as limitações que a FES apresenta..$^{45-47}$

A Tabela 3S, material suplementar, informa diversos parâmetros e rendimentos da produção de celulases por micro-organismos. O estudo da produção de enzimas celulolíticas encontra-se bastante desenvolvido atualmente, concernente à forma de condução dos processos.

De forma geral, na maior parte dos trabalhos reportados na literatura, os materiais utilizados para a produção de celulases são de origem lignocelulósica ou celulósica pura. Entretanto, o efeito indutor de espécies de menores massas moleculares tem sido rastreado há muito tempo. Mandels e colaboradores compararam o efeito de diversos oligo e polissacarídeos na indução de celulases de T. viride, expressas por suas atividades em CMC, obtendo como os de maior potencial: lactose, nigerose, lichenana, glucana de cevada, e principalmente soforose, que apresentou um poder indutor cerca de 2500 vezes maior que o observado anteriormente utilizando-se celobiose. ${ }^{4,6}$ Este forte poder indutor da soforose tem sido reafirmado por alguns autores sendo, por isso, alvo de muitos estudos, como o de Nogawa e colaboradores, que verificaram em $T$. reesei $\mathrm{PC}-3-7$ um forte poder indutor sobre a atividade de endoglucanase, quando essa linhagem foi incubada com concentrações de substrato até cerca de $250 \mathrm{mg} \mathrm{L}^{-1}$, tendo ocorrido a partir desse valor uma estagnação da indução. Já para a linhagem QM 9414 dessa mesma espécie, concentrações acima de $250 \mathrm{mg} \mathrm{L}^{-1}$ mostraram-se prejudiciais à célula, denotada pela redução da atividade enzimática. Esses autores também estudaram a utilização de L-sorbose na indução da produção de endoglucanase, obtendo níveis de expressão ainda maiores que os observados para a soforose na linhagem PC-3-7, porém atividades inferiores na linhagem QM 9414. ${ }^{48}$ Por fim, os resultados de outro trabalho que utilizou a mesma linhagem, T. reesei PC-3-7, corroboraram a supremacia da soforose em induzir a produção de endoglucanases, dessa vez quando comparada ao dissacarídeo lactose. No entanto, quando se adicionou celobiose juntamente à lactose na indução de enzimas celulolíticas, os autores observaram um efeito indutor claramente sinérgico que proporcionou produção enzimática cerca de cinco vezes maior que a observada quando soforose foi utilizada. ${ }^{49}$

Castro comparou a produção de EnG e BG por Trichoderma reesei e Humicola grisea, quando cultivadas em substratos insolúveis (celulignina de bagaço de cana-de-açúcar e avicel) e solúveis (CMC e celobiose). Foram observadas cinéticas mais lentas de produção das enzimas quando fontes insolúveis foram utilizadas, especialmente a de origem lignocelulósica, devido a um período inicial de aclimatação das células a essa matéria-prima. Já quando CMC e celobiose foram consideradas, os tempos correspondentes à produção enzimática máxima foram antecipados em cerca de $50 \mathrm{~h}$. Ainda, nesse estudo pôde-se concluir que na síntese das enzimas do complexo celulolítico pelos fungos T. reesei Rut C30 e Humicola grisea var. thermoidea, não há correlação direta com a fonte de carbono utilizada para a indução, visto que mesmo quando as linhagens foram cultivadas na presença apenas de celobiose como substrato, EnG e ExG também foram excretadas pelas células, e que essa síntese não se enquadrava em caráter constitutivo. ${ }^{50}$

\section{Estudos com micro-organismos geneticamente modificados (MGMs)}

Com o intuito de incrementar os níveis de produção de enzimas, diferentes técnicas podem ser utilizadas, dentre as quais as mais comuns concernentes às celulases são a mutação clássica (aleatória) e a expressão gênica.

A mutação clássica vem sendo aplicada há décadas sobre linhagens de Trichoderma reesei (teleomorfo Hypocrea jecorina), gerando diversas linhagens, geralmente agrupadas em séries, dentre as quais a mais reportada é a linhagem Rut C30. Esta linhagem teve seu potencial celulolítico incrementado devido à mutação do gene cre 1 (acarretando menor efeito de repressão catabólica da glicose pelas células, durante a expressão das enzimas) e ao aumento da quantidade de retículo endoplasmático (promovendo aumento nas taxas de $O$-glicosilação das proteínas). ${ }^{1,51} \mathrm{~A}$ genealogia com as principais 
linhagens mutantes de T. reesei é ilustrada pela Figura 4. Dentre as técnicas mais utilizadas para obtenção das linhagens, pode-se citar radiação ultravioleta (linhagens Rut M7, Rut P37), acelerador linear (linhagens QM 9123, QM 9414) e uso de nitrosoguanidina (linhagens Rut NG14 e Rut C30). ${ }^{52,53} \mathrm{O}$ uso de metanossulfonato de etila também foi reportado como agente mutagênico em células de T. citrinoviride, proporcionando três vezes mais atividade de endoglucanase e quatro vezes mais a produção de $\beta$-glicosidase. ${ }^{54}$

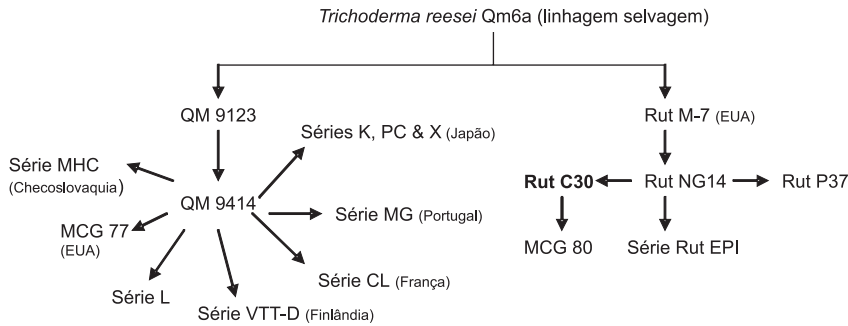

Figura 4. Genealogia dos mutantes de Trichoderma reesei Qm6a. Adaptada da ref. 53

Prabavathy e colaboradores estudaram o método de fusão de protoplastos da linhagem $T$. reesei $\mathrm{PTr} 2$, visando o aumento dos níveis de produção de EnG. Foram obtidas 15 linhagens fusantes, dentre as quais a linhagem 2 apresentou os maiores níveis de expressão, 2,5 vezes superior à da linhagem-mãe..$^{55}$

No que tange à expressão gênica, as formas mais conhecidas de manipulação do conteúdo genético das células são a expressão homóloga e a expressão heteróloga, que são distinguidas conforme a procedência do material genético inserido na célula hospedeira. A Tabela 2 apresenta alguns exemplos de aplicação desses tipos de expressão para a produção de enzimas do complexo celulolítico.

Dentre os organismos hospedeiros mais comumente utilizados para a expressão heteróloga de proteínas, estão a bactéria Escherichia coli e as leveduras Saccharomyces cerevisiae e Pichia pastoris. O sistema de $S$. cerevisiae, embora tenha se mostrado eficiente em alguns casos, apresenta forte tendência a hiperglicosilar (50 a 150 resíduos de manose) as proteínas produzidas, acarretando, no caso das celulases, em uma redução da capacidade destas em adsorver-se em substratos sólidos. ${ }^{1}$ Em relação ao sistema de expressão de $E$. coli, uma das principais desvantagens é a deficiência de etapas pós-traducionais, que decorre em errônea organização estrutural da cadeia polipeptídica, além do fato de esta ficar localizada em corpos de inclusão, os quais dificultam a extração do produto. ${ }^{67,68}$ Por fim, o sistema de expressão de $P$. pastoris, embora tenha apresentado hiperglicosilação em alguns casos, mostra-se como um dos mais adequados dentre os conhecidos atualmente, por proporcionar elevada produção da proteína de interesse, em meio de cultivo relativamente barato, além de conter a enzima $\alpha$-1,3-manosiltransferase no complexo de Golgi, que previne o crescimento excessivo da porção glicídica acoplada à cadeia polipeptídica do produto. ${ }^{69,70}$

Além da estratégia de expressão de celulases de um microorganismo naturalmente ocorrente em células hospedeiras, é possível também que se integrem outros genes no organismo recombinante, visando a expressão integrada das enzimas e do produto final de interesse. Wood e Ingram construíram estável e eficientemente uma linhagem de Klebsiella oxytoca contendo genes de produção de etanol de Zymomonas mobilis e genes de produção de celulases de Clostridium thermocellum. ${ }^{71}$ Posteriormente, os mesmos autores reportaram um estudo mais aprofundado sobre o organismo recombinante produzido, envolvendo a análise de seu fluxo metabólico, para o aumento da produtividade em etanol. ${ }^{72}$ Mais recentemente, Zhou e colaboradores utilizaram a mesma bactéria, $K$. oxytoca, já contendo os genes de produção de etanol de Z. mobilis incorporados em seu cromossomo, como hospedeiro dos genes de síntese de endoglucanase de Erwinia chrysantemi, de forma a atuarem sinergicamente com $\beta$-glicosidase naturalmente ocorrente na bactéria hospedeira, permitindo que o micro-organismo recombinante gerado metabolizasse fontes celulósicas integralmente, gerando como produto etanol, em apenas uma etapa. ${ }^{73}$

\section{PRINCIPAIS APLICAÇÕES DAS CELULASES}

A produção de celulases em escala industrial começou em meados da década de 80, visando sua aplicação como um aditivo para ração animal, de forma a aumentar a digestibilidade de rações por ruminantes e monogástricos. Em seguida, essas enzimas começaram a ser utilizadas como um insumo para a indústria de alimentos, cujo

Tabela 2. Exemplos de produção de celulases utilizando-se técnicas de modificação genética

\begin{tabular}{|c|c|c|c|}
\hline Enzima & Organismo doador & Organismo hospedeiro & Ref. \\
\hline \multicolumn{4}{|l|}{ Expressão homóloga } \\
\hline Celobio-hidrolase II & \multicolumn{2}{|c|}{ T. reesei TU-6 } & 56 \\
\hline Endoglucanase & \multicolumn{2}{|c|}{ T. reesei Cel61A } & 57 \\
\hline \multicolumn{4}{|l|}{ Expressão heteróloga } \\
\hline$\beta$-glicosidase & Physarum polycephalum & E. coli & 58 \\
\hline$\beta$-glicosidase & Cellulomonas biazotea & S. cerevisiae & 59 \\
\hline$\beta$-glicosidase & Orpinomyces PC-2 & Saccharomyces cerecisiae & 60 \\
\hline $\begin{array}{l}\text { Endoglucanase } \\
\beta \text {-glicosidase }\end{array}$ & Bacillus subtilis CD4 & Escherichia coli & 61 \\
\hline Endoglucanase & Clostridium thermocellum & S. cerevisiae & 62 \\
\hline Endoglucanase & Melanocarpus albomyces & T. reesei & 63 \\
\hline Endoglucanase & Orpinomyces joyonii & E. coli & 64 \\
\hline Celobio-hidrolase & Phanerochaete chrysosporium & E. coli & 65 \\
\hline Endoglucanase & T. pseudokoningii $\mathrm{S} 38$ & T. reesei QM9414 & 66 \\
\hline Celobio-hidrolase & T. reesei & Pichia pastoris & 67 \\
\hline
\end{tabular}


objetivo era de melhorar propriedades sensoriais de massas. Nesse setor, as celulases também começaram a atuar no processamento de bebidas, promovendo a clarificação de sucos de frutas e vinhos e a manutenção de uma reologia estável do produto final. Posteriormente, as enzimas celulolíticas começaram a ser utilizadas em larga escala nas seguintes indústrias: têxtil, nos então implementados processos de biopolimento (desfibrilação de tecidos como algodão, linho, lã e viscose) e bioestonagem (amaciamento e desbotamento do brim); de polpa e papel, para a modificação controlada de propriedades mecânicas da polpa e liberação de tintas da superfície das fibras a ser recicladas; e em lavanderia, de forma a aumentar o brilho, a remoção de sujeiras e a maciez dos tecidos, além de amenizar o desgaste das peças, notado pela formação de fiapos e pelotas após sucessivas lavagens. ${ }^{74-80}$

Já na década de 90, as celulases, juntamente com as hemicelulases, representavam mais de $20 \%$ do mercado mundial de enzimas. ${ }^{77}$ No que tange ao cenário nacional, em 2008, apenas considerando-se importações e exportações brasileiras, as celulases movimentaram um montante de USD 1,35 milhão. ${ }^{81}$

\section{Hidrólise de materiais lignocelulósicos}

Uma das mais emergentes aplicações das enzimas do complexo celulolítico atualmente é a hidrólise de biomassas. As matérias-primas de origem lignocelulósica, como apresentado na Tabela $1 \mathrm{~S}$ - material suplementar, contêm de 20 a $60 \%$ de celulose, que pode ser totalmente convertida em glicose, por ação enzimática. Em etapas seguintes, esse monossacarídeo pode ser utilizado como bloco de construção para a obtenção de uma imensa gama de produtos, que abrange desde biocombustíveis até polímeros, sendo o etanol uma das moléculas de maior interesse. Tais tecnologias se enquadram no conceito de biorrefinarias celulósicas, as quais visam o aproveitamento integral e integrado dos resíduos agroindustriais gerados em uma determinada cadeia produtiva, de modo a agregar valor à mesma. ${ }^{82}$

A sacarificação da celulose pode ser conduzida de duas formas principais: por tratamento químico (utilizando-se ácido diluído ou concentrado) ou por rota enzimática, utilizando-se as celulases. ${ }^{83}$

A utilização de celulases na hidrólise da celulose ocorre em condições mais brandas de pressão, temperatura e $\mathrm{pH}$ do que os processos químicos, e exibe elevada especificidade, eliminando a chance de ocorrência de substâncias tóxicas (furfurais e derivados de lignina) às células microbianas que serão utilizadas para fermentação do meio hidrolisado. Na rota enzimática, embora o custo de produção dos biocatalisadores ainda seja alto, são detectados pontos de economia no processo, tanto do ponto de vista energético, como metalúrgico, visto que os equipamentos podem ser confeccionados com materiais menos nobres. ${ }^{84}$

A hidrólise enzimática da celulose e conversão dos açúcares liberados em moléculas de interesse, tal como o etanol, podem ser conduzidas de forma sequencial (processo HSF, hidrólise separada da fermentação) ou simultânea (SSF, sacarificação simultânea à fermentação). ${ }^{83}$

$\mathrm{O}$ processo SSF contribui com menor custo de investimento à planta, visto que nele são agrupadas duas etapas em um mesmo vaso reacional. Nessa forma de condução, as enzimas são menos passíveis de inibição pelos produtos de hidrólise, pois a glicose liberada é concomitantemente fermentada. A manutenção de uma baixa concentração de glicose no meio também favorece o equilíbrio das demais reações de hidrólise, no sentido de formação de mais produto, além de reduzir riscos de contaminação no sistema. ${ }^{83}$

Já o processo HSF apresenta como uma das principais vantagens frente ao SSF, a possibilidade de ambas as etapas, de hidrólise e de fermentação, serem conduzidas em suas condições ótimas. Conforme discutido, as celulases comumente apresentam melhor atividade catalítica em temperaturas acima de $50{ }^{\circ} \mathrm{C}$, bem acima da temperatura ideal para a etapa fermentativa. Nesse caso, como não há matériaprima em suspensão durante a fermentação, as células podem ser recicladas ao sistema. No entanto, essa estratégia apresenta como desvantagens: o acúmulo de açúcares intermediários da hidrólise, causando inibição às enzimas; e redução na conversão final de glicose, devido à adsorção de parte do açúcar no sólido residual da hidrólise. ${ }^{83}$

Considerando-se globalmente a conversão de biomassas lignocelulósicas em etanol, a seção de conversão da planta pode ainda ser constituída por uma etapa para fermentação de pentoses, majoritariamente xilose, provenientes da fração hemicelulósica das matériasprimas. À realização da fermentação de pentoses e hexoses (glicose) em apenas um vaso reacional dá-se o nome de cofermentação (CF). A condução da cofermentação concomitantemente à hidrólise das frações celulósica e/ou hemicelulósica compreende o processo SSCF (sacarificação simultânea à cofermentação). Por fim, na forma mais integrada de condução das etapas de conversão, nomeada Bioprocesso Consolidado (BPC), a produção enzimática, hidrólise da celulose e hemicelulose e a fermentação da glicose e xilose, acontecem em um mesmo equipamento. ${ }^{1,85}$ As formas de condução integrada dos processos de hidrólise e fermentação, visando-se a obtenção de etanol, encontram-se ilustradas na Figura 5.

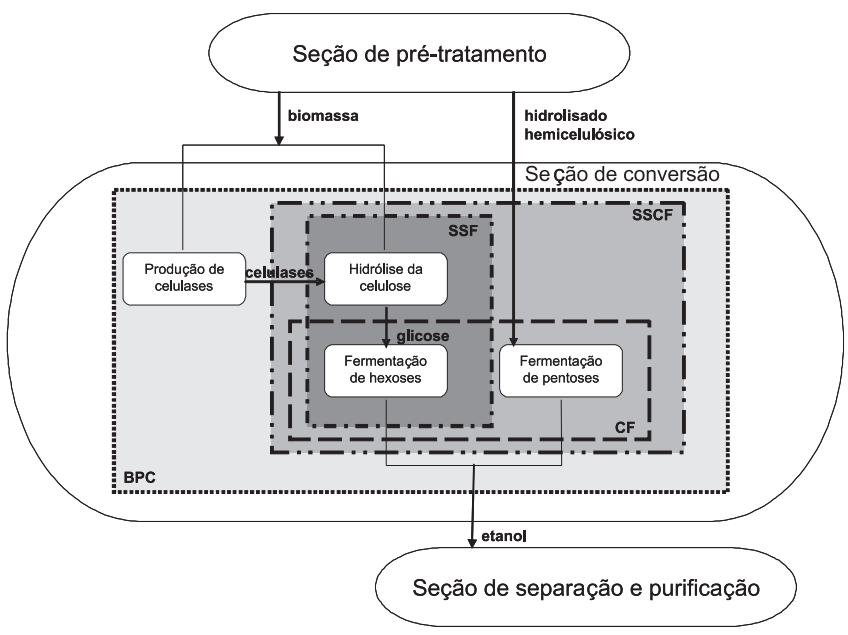

Figura 5. Formas de integração das etapas de conversão de biomassas lignocelulósicas em etanol. Adaptada da ref. 85. As linhas tracejadas representam possibilidades de integração das etapas de conversão e as linhas contínuas representam as fronteiras das seções de uma planta do processo; SSF: Sacarificação simultânea à fermentação; CF: Cofermentação; SSCF: Sacarificação simultânea à cofermentação; BPC: Bioprocesso consolidado

Sob esse aspecto, a Tabela 4S, material suplementar, informa valores de parâmetros importantes do processo de hidrólise da celulose. Dentre os trabalhos reportados, a grande maioria que avalia a hidrólise da celulose para fermentação do monossacarídeo tem por propósito obter como produto final o etanol, à exceção de dois, que enfocam seus trabalhos na conversão de glicose em ácido lático. ${ }^{86,87}$ Há grande variação nos valores das cargas de enzimas utilizadas, bem como das concentrações máximas de produto obtidas durante as hidrólises, o que se justifica, principalmente, por três motivos: as distintas metodologias de quantificação de celulases utilizadas pelos autores, que ora se baseiam nas definições de atividade fornecidas pelos fornecedores das enzimas, outras vezes se referem à definição clássica reportada por Ghose ${ }^{88}$ ou ainda lançam mão de suas próprias metodologias; pelas diferentes técnicas analíticas utilizadas 
na determinação da concentração dos açúcares liberados; e pela concentração de substrato no sistema, fator diretamente relacionado à taxa de diluição dos hidrolisados e à carga enzimática.

É notória a imprescindibilidade de pré-tratamento aos materiais utilizados para os processos de hidrólise. Segundo Van Wyk, a adsorção das celulases em substratos celulósicos insolúveis é facilitada quando estes são submetidos previamente a tratamentos, sejam eles químicos ou termopressurizados, que promovem, pela remoção de frações indesejáveis nesse processo (lignina e hemicelulose), um aumento na área superficial exposta à ação enzimática e a redução da cristalinidade deste glicopolissacarídeo ${ }^{89} \mathrm{Um}$ recurso para o aumento da eficiência de hidrólise que vem sendo reportado é a adição de surfactantes ao meio reacional, cujo intuito é promover maior adsorção das celulases ao polímero celulósico. Alkasrawi e colaboradores verificaram que a suplementação do meio hidrolítico com $2,5 \mathrm{~g} \mathrm{~L}^{-1} \mathrm{de}$ tween-20 proporcionou um aumento de $10 \%$ na conversão de celulose em glicose. Embora a exata ação do surfactante no sistema ainda não esteja completamente elucidada, os autores levantaram a hipótese de que esta molécula se liga à lignina, prevenindo a indesejável adsorção das celulases a essa fração e acarretando, consequentemente, maior disponibilidade das enzimas para se ligarem à celulose..$^{90}$

A hidrólise enzimática da celulose, via de regra, tem seu rendimento aumentado com incrementos na carga enzimática, até uma concentração limite, a partir da qual não é compensatório continuar adicionando enzimas ao processo, pois os sítios da matriz do substrato já se encontram saturados pelos biocatalisadores. Wilkins e colaboradores avaliaram o efeito da concentração de celulases sobre a hidrólise do bagaço de frutas cítricas, pela utilização dos produtos comerciais Celuclast 1.5L e Novozym 188, da empresa Novozymes, em um processo do tipo SSF, e verificaram que em concentrações a partir de $13 \mathrm{UI} \mathrm{g}^{-1}$ e $0,02 \mathrm{FPU} \mathrm{g}^{-1}$, respectivamente, o rendimento final no produto de interesse, etanol, não era mais incrementado. ${ }^{91}$ Em muitos casos, ainda, é necessária a suplementação dos preparados adicionados no meio reacional, utilizando-se $\beta$-glicosidase, com o intuito de promover a redução na inibição de endo- e exoglucanase por seus produtos de hidrólise (especialmente celobiose) e aumentar a conversão final do substrato em glicose. ${ }^{92-94}$

\section{TENDÊNCIAS FUTURAS PARA A PRODUÇÃO E APLICAÇÃO DE CELULASES}

A produção de celulases e sua aplicação na hidrólise de materiais lignocelulósicos são tecnologias em fase de desenvolvimento, para as quais determinadas ferramentas e estratégias podem ser aplicadas visando seu aumento de produtividade e economicidade. Dentre as possibilidades, são apontadas a seguir duas, com elevado potencial de sucesso.

$\mathrm{O}$ conceito de engenharia de produto pode ser aplicado em processos de produção de celulases, visando a obtenção de preparados enzimáticos com proporções ideais entre as diversas enzimas do complexo celulolítico, em particular EnG e BG. O formulado ideal pode ser obtido pelo cocultivo de linhagens superprodutoras dos principais tipos de celulases; ${ }^{95}$ pela produção em separado das celulases e posterior mistura dos extratos, em proporções pré-otimizadas; ${ }^{92-94,96-100}$ ou ainda pela incorporação controlada de genes de celulases em organismos hospedeiros, de forma que a célula modificada já excrete as enzimas em proporções ideais. ${ }^{61}$

No âmbito da produção de etanol a partir de materiais lignocelulósicos, as celulases são insumos que impactam significativamente o processo, podendo representar até $18 \%$ do custo operacional de uma planta. ${ }^{101,102}$ Dessa forma, torna-se necessário o estudo de operações unitárias que permitam o aproveitamento e reciclo desses biocatalisadores ao reator de hidrólise, tais como processos de separação por membranas. Mores e colaboradores estudaram o uso de módulos de microfiltração e ultrafiltração, respectivamente, para a separação da biomassa residual da hidrólise e a recuperação de celulases de Trichoderma reesei. Os autores apresentaram um estudo preliminar de impactos econômicos no uso de membranas para o reciclo de celulases, em processo para produção de etanol, e verificaram que com um fluxo de $50 \mathrm{~L} \mathrm{~m}^{-2} \mathrm{~h}^{-1}$, a redução no custo de produção do produto final é de 0,048 USD L ${ }^{-1} \cdot{ }^{103}$ Entende-se, portanto, que o reciclo de celulases é uma estratégia que deve ser investigada mais profundamente, por ser uma provável alternativa para a viabilidade econômica de processos de segunda geração para produção de etanol.

\section{MATERIAL SUPLEMENTAR}

No material suplementar disponível em http://quimicanova.sbq. org.br, na forma de arquivo PDF, com acesso livre, encontram-se tabelas referentes à composição de materiais lignocelulósicos, às principais propriedades de enzimas do complexo celulolítico, levantamento bibliográfico da produção de celulases e sua aplicação na hidrólise de biomassas (Tabelas 1S a 4S).

\section{AGRADECIMENTOS}

À Profa. S. G. F. Leite e ao Dr. A. M. Sanseverino pelas valiosas sugestões sobre o texto.

\section{REFERÊNCIAS}

1. Lynd, L. R.; Weimer, P. J.; van Zyl, W. H.; Pretorius, I. S.; Microbiol. Mol. Biol. Rev. 2002, 66, 506.

2. Tolan, J. S.; Clean Technol. Environ. Policy 2002, 3, 339

3. Reese, E. T.; Biotechnol. Bioeng. Symp. 1976, 6, 9.

4. Mandels, M.; Parrish, F. W.; Reese, E. T.; J. Bacteriol. 1962, 83, 400.

5. Mandels, M.; Weber, J.; Parizek, R.; Appl. Microbiol. 1971, 21, 152.

6. Mandels, M.; Reese, E. T.; J. Bacteriol. 1960, 79, 816.

7. Mandels, M.; Reese, E. T.; J. Bacteriol. 1957, 73, 269.

8. http://www.nrel.gov/research_review/pdfs/2003/36178c.pdf, acessada em Abril 2009.

9. http://www.nrel.gov/docs/gen/fy04/36831g.pdf, acessada em Abril 2009.

10. Focus Catal. 2004, 4, 6.

11. http://www.iogen.ca/, acessada em Abril 2009.

12. Bhat, M. K.; Bhat, S.; Biotechnol. Adv. 1997, 15, 583.

13. Szengyel, Z.; Tese de Doutorado, Lund University, Suécia, 2000.

14. http://www.sidra.ibge.gov.br, acessada em Fevereiro 2009.

15. Carvalho, F. C.; Informações Econômicas. 1992, 22, 31

16. Jeffries, T. W.; Biodegradation 1990, 1, 163.

17. Higuchi, T.; Experientia 1982, 38, 159.

18. Ramos, L. P.; Quim. Nova 2003, 26, 863.

19. Mosier, N.; Wyman, C.; Dale, B.; Elander, R.; Lee, Y. Y.; Holtzapple, M.; Ladish, M.; Bioresour. Technol. 2005, 96, 673.

20. Henrissat, B. A.; Biochem. J. 1991, 280, 309.

21. Kleman-Leyer, K. M.; Siika-Aho, M.; Teeri, T. T.; Kirk, T. K.; App. Environ. Microbiol. 1996, 62, 2883

22. http://www.vtt.fi/inf/pdf/publications/2004/P550.pdf, acessada em Maio 2009.

23. Zhang, Y. H. P.; Lynd, L. R.; Biotechnol. Bioeng. 2004, 88, 797.

24. Awafo, V. A.; Tese de Doutorado, McGill University, Canadá, 1997.

25. Lynd, L. R.; Zhang, Y.; Biotechnol. Bioeng. 2002, 77, 467.

26. Zhang, C.; Xing, X. H.; Liu, M. S.; Biochem. Eng. J. 2004, 19, 181.

27. Lima, A. L. G.; Nascimento, R. P.; Bon, E. P. S.; Coelho, R. R. R.; Enzyme Microb. Technol. 2005, 37, 272.

28. Jang, H. D.; Chen, K. S.; World J. Microbiol. Biotechnol. 2003, 19, 263.

29. Huang, X. P.; Monk, C.; World J. Microbiol. Biotechnol. 2004, $20,85$. 
30. Tuohy, M. G.; Walsh, D. J.; Murray, P. G.; Claeyssens, M.; Cuffe, M. M.; Savage, A. V.; Coughlan, M. P.; Biochim. Biophys. Acta 2002, 1596, 366.

31. Anand, L.; Vithayathil, P. J.; J. Ferm. Bioeng. 1989, 67, 380.

32. Yun, S. I.; Jeong, C. S.; Chung, D. K.; Choi, H. S.; Biosci. Biotechnol. Biochem. 2001, 65, 2028.

33. Akiba, S.; Kimura, Y.; Yamamoto, K.; Kumagai, H.; J. Ferm. Bioeng. 1995, 79, 125.

34. Yazdi, M. T.; Krosravi, A.; Nemati, M.; Motlagh, N.; World J. Microbiol. Biotechnol. 2003, 19, 79.

35. Pandey, A.; Biochem. Eng. J. 2003, 13, 81.

36. Raghavarao, K. S. M. S.; Ranganathan, T. V.; Karanth, N. G.; Biochem. Eng. J. 2003, 13, 127.

37. Raimbault, M.; Electronic J. Biotechnol. 1998, 1, 174.

38. Robinson, T.; Nigam, P.; Biochem. Eng. J. 2003, 13, 197.

39. Gervais, P.; Molim, P.; Biochem. Eng. J. 2003, 13, 85.

40. Mitchell, D. A.; Berovic, M.; Krieger, N.; Adv. Biochem. Eng. Biotechnol. 2000, 68, 61 .

41. Santos, M. M.; Rosa, A. S.; Dal'Boit, S.; Mitchell, D. A.; Krieger, N.; Bioresour. Technol. 2004, 93, 261.

42. Durand, A.; Biochem. Eng. J. 2003, 13, 113.

43. Suryanarayan, S.; Biochem. Eng. J. 2003, 13, 189.

44. von Meien, O. F.; Luz, L. F. L.; Mitchell, D. A.; Perez-Correa, J. R.; Agosin, E.; Fernandez-Fernandez, M.; Arcas, J. A.; Chem. Eng. Sci. 2004, 59, 4493.

45. Mitchell, D. A.; von Meien, O. F.; Krieger, N.; Dalsenter, F. D. H.; Biochem. Eng. J. 2004, 17, 15.

46. Banerjee, R.; Bhattacharyya, B. C.; Biochem. Eng. J. 2003, 13, 149.

47. Mitchell, D. A.; von Meien, O. F.; Krieger, N.; Biochem. Eng. J. 2003, $13,137$.

48. Nogawa, M.; Goto, M.; Okada, H.; Morikawa, Y.; Curr. Genet. 2001, 38, 329.

49. Morikawa, Y.; Ohashi, T.; Mantani, O.; Okada, H.; Appl. Microbiol. Biotechnol. 1995, 44, 106.

50. Castro, A. M.; Dissertação de Mestrado, Universidade Federal do Rio de Janeiro, Brasil, 2006.

51. Kubiceck, C. P.; Messner, R.; Gruber, F.; Mandels, M.; Kubiceck-Pranz, E. M.; J. Biol. Chem. 1993, 268, 19364.

52. Seidl, V.; Gamauf, C.; Druzhinina, I. S.; Seiboth, B.; Hartl, L.; Kubicek, C. P.; BMC Genomics 2008, 9, 327.

53. Cen, P.; Xia, L.; Adv. Biochem. Eng. Biotechnol. 1999, 65, 70.

54. Chandra, M.; Kalra, A.; Sangwan, N. S.; Gaurav, S. S.; Darokar, M. P.; Sangwan, R. S.; Bioresour. Technol. 2009, 100, 1659.

55. Prabavathy, V. R.; Mathivanan, N.; Sagadevan, E.; Murugesan, K.; Lalithakumari, D.; Enzyme Microb. Technol. 2006, 38, 719.

56. Mach, R. L.; Schindler, L.; Kubiceck, C. P.; Curr. Genet. 1994, 25, 567.

57. Karlsson, J.; Saloheimo, M.; Siika-Aho, M.; Tenkanen, M.; Penttilä, M.; Tjerneld, F.; Eur. J. Biochem. 2001, 268, 6498.

58. Hayase, M.; Maekawa, A.; Yubisui, T.; Minami, Y.; Int. J. Biochem. Cell Biol. 2008, 40, 2141.

59. Parvez, S.; Ukhtar, Z.; Rashid, F.; Rajoka, M. I.; Afr. J. Biotechnol. 2004, 3,112 .

60. Li, X. L.; Ljungdahl, L.; Ximenes, E.; Chen, H.; Falix, C.; Cotta, M.; Dien, B.; Appl. Biochem. Biotechnol. 2004, 113-116, 233.

61. Srivastava, K. K.; Verma, P. K.; Srivastava, R.; Biotechnol. Lett. 1999, 21, 293.

62. Chung, D. K.; Shin, D. H.; Kim, B. W.; Nam, J. K.; Han, I. S.; Nam, S. W.; Biotechnol. Lett. 1997, 19, 503.

63. Haakana, H.; Miettinen-Oinonen, A.; Joutsjoki, V.; Mäntilä, A.; Suominen, P.; Vehmaanperä, J.; Enzyme Microb. Technol. 2004, 34, 159.

64. Ye, X. Y.; Ng, T. B.; Chen, K. J.; Int. J. Biochem. Cell Biol. 2001, 33, 87.

65. Howard, R. L.; Masoko, P.; Abotsi, E.; Afr.J. Biotechnol. 2003, 2, 296.

66. Yao, Q.; Sun, T. T.; Liu, W. F.; Chen, G. J.; Biosci. Biotechnol. Biochem. 2008, 72, 2799.
67. Godbole, S.; Decker, S. R.; Nieves, R. A.; Adney, W. S.; Vinzant, T. B.; Baker, J. O.; Thomas, S. R.; Himmel, M. E.; Biotechnol. Prog. 1999, 15 , 828.

68. Lodish, H.; Berk, A.; Matsudaira, P.; Kaiser, C. A.; Krieger, M.; Scott, M. P.; Zipursky, L.; Darnell, J.; Molecular Cell Biology, $5^{\text {th }}$ ed., W. H. Freeman and company: New York, 2004

69. Bretthauer, R. K.; Trends Biotechnol. 2003, 21, 459.

70. Cereghino, J. L.; Cregg, J. M.; FEMS Microbiol. Rev. 2000, $24,45$.

71. Wood, B. E.; Ingram, L. O.; Appl. Environ. Microbiol. 1992, 58, 2103.

72. Ingram, L. O.; Gómez, P. F.; Lai, X.; Moniruzzaman, M.; Wood, B. E.; Yomano, L. P.; York, S. W.; Biotechnol. Bioeng. 1998, 58, 201.

73. Zhou, S.; Davis, F. C.; Ingram, I. O.; Appl. Environ. Microbiol. 2001, 67, 6.

74. Tolan, J. S.; Foddy, B.; Adv. Biochem. Eng. Biotechnol. 1999, 65, 41.

75. Cunha, R. T.; Dissertação de Mestrado, Universidade Federal do Rio de Janeiro, Brasil, 2002.

76. Kirk, T. K.; Jeffries, T. W. Em Enzymes for Pulp and Paper Processing; Jeffries, T. W.; Viikari, L., eds.; ACS Symposium Series 655: Washington, 1996

77. Bhat, M. K.; Biotechnol. Adv. 2000, 18, 355 .

78. Jeffries, T. W.; Sykes, M. S.; Rutledge-Cropsey, K.; Klungness, J. H.; Abubakr, S. Em Biotechnology in the Pulp and Paper Industry: Recent Advances in Applied and Fundamental Research; Srebotnik, E.; Messner, K., eds.; Facultas-Universitätsverlag: Viena, 1996.

79. Jeffries, T.; Klungness, J. H.; Sykes, M. S.; Rutledge-Cropsey, K.; Recycling Synposium - TAPPI Notes, TAPPI Press: Atlanta, 1993.

80. Coelho, M. A. Z.; Salgado, A. M.; Ribeiro, B. D.; Tecnologia Enzimática, $1^{\text {a }}$ ed., EPUB: Rio de Janeiro, 2008

81. http://aliceweb.desenvolvimento.gov.br/, acessada em Fevereiro 2009.

82. http://www1.eere.energy.gov/biomass/docs/esppp.ppt, acessada em Maio 2009.

83. Olofsson, K.; Bertilsson, M.; Lidén, G.; Biotechnol. Biofuels. 2008, 1, 7.

84. Badger, P. C. Em Trends in New Crops and New Uses; Janick, J.; Whipkey, A., eds.; ASHS Press: Alexandria, 2002.

85. Cardona, C. A.; Sánchez, O. J.; Bioresour. Technol. 2007, 98, 2415.

86. Miura, S.; Arimura, T.; Itoda, N.; Dwiarti, L.; Feng, J. B.; Bin, C. H.; Okabe, M.; J. Biosci. Bioeng. 2004, 97, 153.

87. Tanaka, T.; Hoshina, M.; Tanabe, S.; Sakai, K.; Ohtsubo, S.; Taniguchi, M.; Bioresour. Technol. 2006, 97, 211.

88. Ghose, T. K.; Pure Appl. Chem. 1987, 59, 257.

89. van Wyk, J. P. H.; Biotechnol. Tech. 1997, 11, 443.

90. Alkasrawi, M.; Eriksson, T.; Borjesson, J.; Wingren, A.; Galbe, M.; Tjerneld, F.; Zacchi, G.; Enzyme Microb. Technol. 2003, 33, 71.

91. Wilkins, M. R.; Widmer, W. W.; Grohmann, K.; Proc. Biochem. 2007, 42,1614

92. Kádár, Z.; Szengyel, Z.; Réczey, K.; Ind. Crop. Prod. 2004, 20, 103.

93. Saha, B. C.; Iten, L. B.; Cotta, M. A.; Wu, Y. V.; Proc. Biochem. 2005 , 40,3693

94. Sendelius, J.; Dissertação de Mestrado, Lund University, Suécia, 2005.

95. Wen, Z.; Liao, W.; Chen, S.; Appl. Biochem. Biotechnol. 2005, 121-124, 93.

96. Xiao, Z.; Zhang, X.; Gregg, D. J.; Saddler, J. N.; Appl. Biochem Biotechnol. 2004, 113-116, 1115.

97. Pan, X.; Zhang, X.; Gregg, D. J.; Saddler, J. N.; Appl. Biochem. Biotechnol. 2004, 113-116, 1103.

98. Aguiar, C. L.; Menezes, T. J. B.; Biotecnologia Ciência \& Desenvolvimento. 2002, 26, 52.

99. Öhgren, K.; Rudolf, A.; Galbe, M.; Zacchi, G.; Biom. Bioen. 2006, 30, 863.

100. Imai, M.; Ikari, K.; Suzuki, I.; Biochem. Eng. J. 2004, 17, 79.

101. Philippidis, G. P.; Hatzis, C.; Biotechnol. Prog. 1997, 13, 222.

102. Wingren, A.; Galbe, M.; Zacchi, G.; Biotechnol. Prog. 2003, 19, 1109.

103. Mores, W. D.; Knutsen, J. S.; Davis, R. H.; Appl. Biochem. Biotechnol. 2001, 91-93, 297. 
Aline Machado de Castro*

Centro de Pesquisas e Desenvolvimento Leopoldo Américo Miguez de Mello, PETRÓLEO BRASILEIRO S.A., Av. Horácio Macedo, 950, Ilha do Fundão, 21941-920 Rio de Janeiro - RJ, Brasil

Nei Pereira Jr.

Escola de Química, Universidade Federal do Rio de Janeiro, 21945-970 Rio de Janeiro - RJ, Brasil

Tabela 1S. Composição de alguns materiais lignocelulósicos

\begin{tabular}{|c|c|c|c|c|}
\hline \multirow{2}{*}{ Material } & \multicolumn{3}{|c|}{ Composição (\%) } & \multirow{2}{*}{ Ref } \\
\hline & Celulose & Hemicelulose & Lignina & \\
\hline Bagaço de cana (Saccharum officinarum) & 36 & 28 & 20 & 1 \\
\hline Palha de cana & 36 & 21 & 16 & 2 \\
\hline Palha de milho (Zea mays) & 36 & 28 & 29 & 1 \\
\hline Sabugo de milho & 36 & 28 & NR & 1 \\
\hline Palha de trigo (Triticum aestivum) & 39 & 36 & 10 & 3 \\
\hline Palha de cevada (Hordeum vulgare) & 44 & 27 & 7 & 3 \\
\hline Farelo de cevada & 23 & 33 & 21 & 4 \\
\hline Palha de arroz (Oryza sativa) & 33 & 26 & 7 & 3 \\
\hline Casca de arroz & 36 & 20 & 19 & 5 \\
\hline Palha de aveia (Avena sativa) & 41 & 16 & 11 & 3 \\
\hline Palha de algodão (Gossypium hirsutum) & 42 & 12 & 15 & 6 \\
\hline Casca de amendoim (Arachis hypogaea) & 38 & 36 & 16 & 6 \\
\hline Douglas fir (Pseudotsuga menziesii) & 50 & 18 & 28 & 5 \\
\hline Pinheiro (Pinus sp.) & 44 & 26 & 29 & 1 \\
\hline Salgueiro (Salix alba) & 37 & 23 & 21 & 1 \\
\hline Capim elefante (Pennisetum purpureum) & 32 & 20 & 9 & 2 \\
\hline Resíduos sólidos municipais & 33 & 9 & 17 & 2 \\
\hline Papel & 43 & 13 & 6 & 1 \\
\hline Papelão & 47 & 25 & 12 & 1 \\
\hline Jornal & 62 & 16 & 21 & 2 \\
\hline
\end{tabular}

NR: Valores não reportados 
Tabela 2S. Propriedades cinéticas e físico-químicas das celulases

\begin{tabular}{|c|c|c|c|c|}
\hline Fonte e tipo da enzima & $\mathrm{T}_{\mathrm{o}}\left({ }^{\circ} \mathrm{C}\right) ; \mathrm{pH}_{\mathrm{o}}$ & $\mathrm{K}_{\mathrm{M}} ; \mathrm{V}_{\text {máx }}$ & MM (kDa); pI; \% carboidrato & Referência \\
\hline Caldibacillus cellulovorans Endoglucanase & $80 ; 7,0$ & $3,4^{2} ; 44,7^{3}$ & 85,$1 ; 4,12 ; \mathrm{NR}$ & 7 \\
\hline $\begin{array}{l}\text { Bacillus sp. D04 } \\
\text { Celulase bifuncional }^{1}\end{array}$ & NR; NR & $5,29^{4} ; 214^{5}$ & $35 ; \mathrm{NR}$; NR & 8 \\
\hline $\begin{array}{l}\text { Ceriporiopsis subvermispora } \\
\text { Endoglucanase } \\
\beta \text {-glicosidase }\end{array}$ & $\begin{array}{l}60 ; 3,5 \\
60 ; 4,5\end{array}$ & NR; NR & NR; NR; NR & $\begin{array}{l}9 \\
9\end{array}$ \\
\hline $\begin{array}{l}\text { Trichoderma viride } \\
\text { Endoglucanase }\end{array}$ & $60 ; 4,8$ & NR; NR & NR; NR; NR & 10 \\
\hline Myceliophtohora thermophila Endoglucanase & $65 ; 4,8$ & NR; NR & $100 ; \mathrm{NR} ; \mathrm{NR}$ & 11 \\
\hline $\begin{array}{l}\text { Talaromyces emersonii Endoglucanase I } \\
\beta \text {-glicosidase } \\
\text { Celobiohidrolase IA }\end{array}$ & $\begin{array}{c}75-80 ; 5,5-5,8 \\
70 ; 4,1 \\
78 ; 3,6\end{array}$ & $\begin{array}{l}\mathrm{NR} ; \mathrm{NR} \\
\mathrm{NR} ; \mathrm{NR} \\
2,1^{4} ; 9,2^{6}\end{array}$ & $\begin{array}{l}35 ; \mathrm{NR} ; 27,7 \\
135 ; \mathrm{NR} ; 50 \\
66 ; 4,5 ; 38,2\end{array}$ & $\begin{array}{l}12 \\
13 \\
14\end{array}$ \\
\hline \multicolumn{5}{|l|}{ Humicola insolens } \\
\hline Endoglucanase & $50 ; 5,0$ & NR; NR & $57 ; \mathrm{NR} ; 39,0$ & 15 \\
\hline Exoglucanase & $50 ; 5,0$ & NR; NR & $72 ; \mathrm{NR} ; 26,0$ & 16 \\
\hline$\beta$-glicosidase & $50 ; 5,0$ & NR; NR & $250 ; 4,2 ; 2,5$ & 17 \\
\hline $\begin{array}{l}\text { Humicola grisea var thermoidea } \\
\beta \text {-glicosidase }\end{array}$ & $60 ; 4,0-4,5$ & NR; NR & 156; NR; NR & 18 \\
\hline $\begin{array}{l}\text { Humicola lanuginosa } \\
\beta \text {-glicosidase }\end{array}$ & $60 ; 4,5$ & $0,44^{4} ; \mathrm{NR}$ & $110 ; \mathrm{NR} ; 9,0$ & 19 \\
\hline $\begin{array}{l}\text { Sporotrichum thermophile } \\
\text { Exoglucanase } \\
\beta \text {--glicosidase }\end{array}$ & $\begin{array}{l}63 ; 4,0-5,0 \\
65 ; 5,4\end{array}$ & $\begin{array}{c}\mathrm{NR} ; \mathrm{NR} \\
0,83^{4} ; \mathrm{NR}\end{array}$ & $\begin{array}{c}64 ; 4,5 ; 8,0 \\
240 ; N R ; N R\end{array}$ & $\begin{array}{l}20 \\
21\end{array}$ \\
\hline $\begin{array}{l}\text { Trichoderma harzianum } \\
\beta \text {-glicosidase }\end{array}$ & $45 ; 5,0$ & $0,20^{4} ; 187^{3}$ & $75 ; 8,7 ; \mathrm{NR}$ & 22 \\
\hline $\begin{array}{l}\text { Ruminococcus albus } \\
\beta \text {-glicosidase }\end{array}$ & $37 ; 6,8$ & NR; NR & $100 ; 5,3 ; \mathrm{NR}$ & 23 \\
\hline $\begin{array}{l}\text { Bacteroides succinogenes } \\
\beta \text {-glicosidase }\end{array}$ & $45-50 ; 5,9-6,2$ & $0,40^{4} ; 11,6^{3}$ & $40 ; 4,9 ; \mathrm{NR}$ & 24 \\
\hline $\begin{array}{l}\text { Penicillium funiculosum } \\
\text { endoglucanase } \\
\beta \text {-glicosidase }\end{array}$ & $\begin{array}{l}58 ; 4,8 \\
57 ; 4,9\end{array}$ & $\begin{array}{c}11^{2} ; 0,56^{7} \\
1,75^{4} ; 0,12^{7}\end{array}$ & $\begin{array}{l}\text { 140-190; NR;NR } \\
\text { NR;NR;NR }\end{array}$ & $\begin{array}{l}25 \\
25\end{array}$ \\
\hline $\begin{array}{l}\text { Trichoderma harzianum } \\
\text { endoglucanase } \\
\beta \text {-glicosidase }\end{array}$ & $\begin{array}{c}47-52 ; 4,9-5,1 \\
53-54 ; 5,0\end{array}$ & $\begin{array}{l}19-22^{2} ; 0,07-0,12^{7} \\
1,5-1,5^{4} ; 0,11-0,13^{7}\end{array}$ & $\begin{array}{l}\text { 55-95;NR;NR } \\
\text { NR;NR;NR }\end{array}$ & $\begin{array}{l}26 \\
26\end{array}$ \\
\hline $\begin{array}{l}\text { Aspergillus oryzae } \\
\beta \text {-glicosidase }\end{array}$ & $50 ; 5,0$ & $0,55^{4} ; \mathrm{NR}$ & $43 ; 4,2 ; \mathrm{NR}$ & 27 \\
\hline $\begin{array}{l}\text { Aspergillus niger } \\
\text { endoglucanase } \\
\beta \text {-glicosidase }\end{array}$ & $\begin{array}{l}54 ; 5,1 \\
54 ; 5,0\end{array}$ & $\begin{array}{c}46^{2} ; 1,04^{7} \\
3,28^{4} ; 0,11^{7}\end{array}$ & $\begin{array}{l}\text { 75-105; NR; NR } \\
\text { NR;NR;NR }\end{array}$ & 26 \\
\hline
\end{tabular}

$\mathrm{T}_{\mathrm{o}}$ : Temperatura ótima de atuação; $\mathrm{pH}_{\mathrm{o}}$ : $\mathrm{pH}$ ótimo de atuação; MM: Massa molecular; pI: Ponto isoelétrico; NR: Valores não reportados. ${ }^{1} \mathrm{~A}$ enzima apresentou comportamento característico tanto de endo- como de exoglucanase; Unidades dos valores apresentados: ${ }^{2} \mathrm{~g} \mathrm{~L}^{-1} ;{ }^{3} \mu \mathrm{mol} \mathrm{min}^{-1} \mathrm{mg}^{-1} ;{ }^{4} \mathrm{mM} ;{ }^{5} \mu \mathrm{mol} \mathrm{min}^{-1} ;{ }^{6} \mu \mathrm{mol} \mathrm{min}^{-1} \mathrm{~mL}^{-1} ;{ }^{7} \mu \mathrm{mol} \mathrm{min}^{-1} \mathrm{UI}^{-1}$ 
Tabela 3S. Produção de celulases por micro-organismos

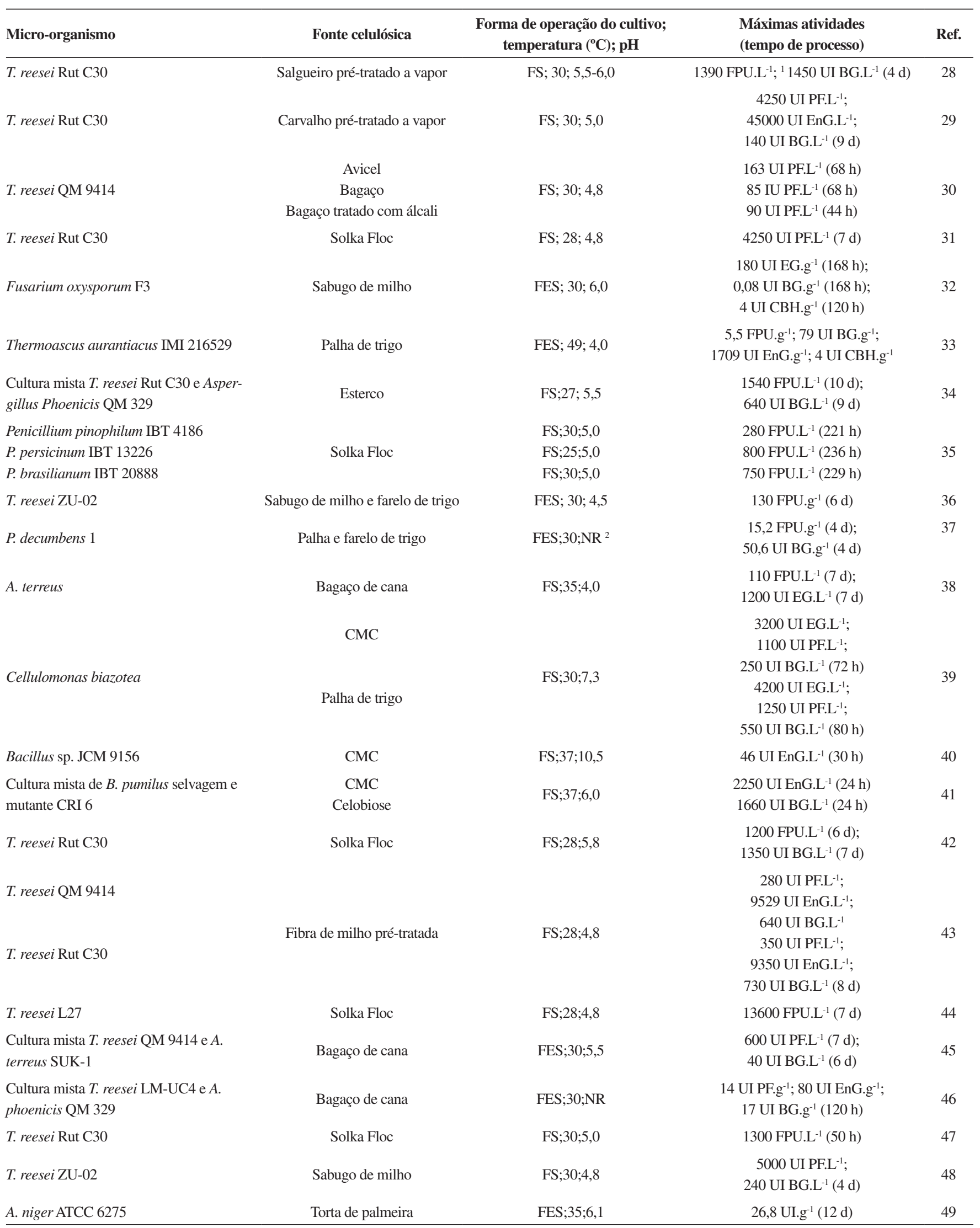


Tabela 4S. Condições de aplicação de celulases na hidrólise de materiais lignocelulósicos

\begin{tabular}{|c|c|c|c|c|c|}
\hline $\begin{array}{l}\text { Fonte das } \\
\text { celulases }\end{array}$ & $\begin{array}{c}\text { Configuração do processo; } \\
\text { temperatura }\left({ }^{\circ} \mathrm{C}\right) ; \mathrm{pH}\end{array}$ & Carga de enzimas & Fonte celulósica & $\begin{array}{l}\text { Teor de produto }\left(\mathrm{g} \mathrm{L}^{-1}\right) \\
\text { (tempo de processo, } \mathrm{h})\end{array}$ & Ref. \\
\hline Multifect $\mathrm{B}^{\circledR, 3}$ & SSF; $50 ; 5,4$ & $5 \mathrm{FPU} \mathrm{g}_{\text {biomassa }}^{-1}$ & Alfafa & $50^{1}(96)$ & 50 \\
\hline Celuclast $1.5 \mathrm{~L}^{\circledR, 4}$ & SSF; 42; NR & $15 \mathrm{FPU} \mathrm{g}^{-1}{ }_{\text {biomassa }}$ & $\begin{array}{c}\text { Eucalipto } \\
\text { Palha de trigo } \\
\text { Bagaço de sorgo }\end{array}$ & $\begin{array}{l}<1^{1}(160) \\
3^{1}(160) \\
2^{1}(160)\end{array}$ & 52 \\
\hline $\begin{array}{l}\text { Celuclast } 1.5 \mathrm{~L}^{\circledR, 4} \\
\text { Novozym } 188^{\circledR, 4}\end{array}$ & SSF; 40; 4,4-5,3 & $\begin{array}{l}15 \mathrm{FPU} \mathrm{g}_{\text {biomassa }}^{-1} \\
15 \mathrm{UI} \mathrm{g}_{\text {biomassa }}^{-1}\end{array}$ & Solka Floc 200 & $5^{1}(24)$ & 53 \\
\hline $\begin{array}{l}\text { Preparados de } \\
\text { Acremonium }^{\circledast, 5}, \\
\text { Meicellase }^{\circledR, 5}\end{array}$ & SHF; $45 ; 4,5$ & $20 \mathrm{U} \mathrm{g}_{\text {biomassa }}^{-1}$ & Sabugo de milho & $\begin{array}{l}25^{1}(72) \\
35^{1}(72)\end{array}$ & 54 \\
\hline Cellulase $\mathrm{Y}^{-\mathrm{NC}^{\circledR}, 7}$ & SHF; $37 ; 5,0$ & $3,3 \mathrm{mg} \mathrm{L}^{-1}$ & Farelo de arroz & $20^{1}(48)$ & 56 \\
\hline $\begin{array}{l}\mathrm{C}-1184^{\circledR, 8} \text { de } A . \\
\text { niger }\end{array}$ & $\mathrm{H} ; 60 ; 5,0$ & $100 \mu \mathrm{g} \mathrm{g}_{\text {biomasa }}^{-1}$ & Casca de arroz & $1,2^{9}(5)$ & 57 \\
\hline $\begin{array}{l}\text { Celuclast }^{\circledR, 4} \\
\text { Novozym } 188^{\circledR, 4}\end{array}$ & $\mathrm{H} ; 50 ; 4,8$ & $40 \mathrm{FPU} \mathrm{g}^{-1}{ }_{\text {celulose }}$ & Softwood & $70^{1}(30)$ & 58 \\
\hline $\begin{array}{l}\text { Celuclast }^{\circledast, 4} \\
\text { Novozym } 188^{\circledast, 4}\end{array}$ & $\mathrm{H} ; 45 ; 4,8$ & $80 \mathrm{FPU} \mathrm{g}^{-1}$ celulose & Madeira Douglas fir & $1,5^{1}(72)$ & 59 \\
\hline $\begin{array}{l}\text { Rapidase } \\
\text { Pomaliq }^{\circledR, 10}\end{array}$ & $\mathrm{H} ; 50 ; 5,0$ & $26 \mathrm{UI} \mathrm{EG} \mathrm{g}^{-1}$ biomassa & Sabugo de milho & $110^{1}(48)$ & 60 \\
\hline $\begin{array}{l}\text { Preparados de } \\
\text { T. viride e A. niger }\end{array}$ & $\mathrm{H} ; 50 ; 4,8$ & $28 \mathrm{U} \mathrm{EG} \mathrm{g}^{-1}$ biomassa & Bagaço de cana & $20{ }^{9}(72)$ & 61 \\
\hline $\begin{array}{l}\text { Celuclast } 1.5 \mathrm{~L} \\
\mathrm{FG}^{\circledast, 4}\end{array}$ & SSF; 42; NR & $15 \mathrm{FPU} \mathrm{g}_{\text {celulose }}^{-1}$ & Sigmacell, ${ }^{, 11}$ & $15,3^{1}(2-4)$ & 65 \\
\hline $\begin{array}{l}\text { Preparados de } T \text {. } \\
\text { viride e A. niger }\end{array}$ & $\mathrm{H} ; 50 ; 4,8$ & $41600 \mathrm{U} \mathrm{g}^{-1}$ celulose & CMC & $0,36^{1}(3)$ & 66 \\
\hline
\end{tabular}

${ }^{1}$ Concentração de produto expressa como glicose; ${ }^{2}$ concentração de produto expressa como glicose e celobiose; ${ }^{3}$ preparados comercializados pela empresa Genencor; ${ }^{4}$ preparados comercializados pela empresa Novozymes; ${ }^{5}$ preparados comercializados pela empresa Meiji Pharmaceutical; ${ }^{6}$ concentração de produto expressa como açúcares totais; ${ }^{7}$ preparados comercializados pela empresa Yakult Pharmaceutical; ${ }^{8}$ preparados comercializados pela empresa Sigma; ${ }^{9}$ concentração de produto expressa como açúcares redutores totais; ${ }^{10}$ preparado comercializado pela empresa Gist Brocades; ${ }^{11}$ celulose microcristalina comercializada pela empresa Sigma Aldrich. NR: Informação não reportada; BG: $\beta$-glicosidase; H: processo em que só a hidrólise foi avaliada, sem a etapa de fermentação; SSF: sacarificação simultânea à fermentação; HSF: hidrólise separada da fermentação; SSCF: sacarificação simultânea à cofermentação. 


\section{REFERÊNCIAS}

1. Olsson, L.; Hahn-hagerdal, B.; Enzyme Microb. Technol. 1996, 18, 312.

2. http://www.hawaii.gov/dbedt/info/energy/transportation/ethanol/studies/ ethano194.pdf, acessada em Maio 2009.

3. Awafo, V. A.; Tese de Doutorado, McGill University, Canadá, 1997.

4. Couto, S. R.; Sanromán, M. A.; Biochem. Eng. J. 2005, 22, 211.

5. Cen, P.; Xia, L.; Adv. Biochem. Eng. Biotechnol. 1999, 65, 70.

6. Ghosh, P.; Singh, A.; Adv. Appl. Microbiol. 1993, 39, 295.

7. Huang, X. P.; Monk, C.; World J. Microbiol. Biotechnol. 2004, 20, 85.

8. Han, S. J.; Yoo, Y. J.; Kang, H. S.; J. Biol. Chem. 1995, 270, 26012.

9. Heidorne, F. O.; Magalhães, P. O.; Ferraz, A. L.; Milagres, A. M. F.; Enzyme Microb. Technol. 2006, 38, 436.

10. Mandels, M.; Reese, E. T.; J. Ind. Microbiol. Biotechnol. 1999, 22, 225

11. Roy, S. K.; Dey, S. K.; Raha, S. K.; Chakrabarty, S. L.; J. Gen. Microbiol. 1990, 136, 1967.

12. Moloney, A. P.; McCrae, S. I.; Wood, T. M.; Couglan, M. P.; Biochem. J. 1985, 225, 365.

13. Coughlan, M. P.; McHale, A.; Methods Enzymol. 1988, 160, 437.

14. Tuohy, M. G.; Walsh, D. J.; Murray, P. G.; Claeyssens, M.; Cuffe, M. M.; Savage, A. V.; Coughlan, M. P.; Biochim. Biophys. Acta. 2002, 1596, 366.

15. Hayashida, S.; Ohta, K.; Mo, K.; Methods Enzymol. 1988, 160, 323.

16. Hayashida, S.; Yoshioka, H.; Agric. Biol. Chem. 1980, 44, 481.

17. Hayashida, S.; Yoshioka, H.; Agric. Biol. Chem. 1980, 44, 1721.

18. Filho, E. X. F.; Can. J. Microbiol. 1996, 42, 1.

19. Bhat, M. K.; Bhat, S.; Biotechnol. Adv. 1997, 15, 583.

20. Anand, L.; Vithayathil, P. J.; J. Ferm. Bioeng. 1989, 67, 380.

21. Fracheboud, D.; Canevascini, G.; Enzyme Microb. Technol. 1989, 11, 220 .

22. Yun, S. I.; Jeong, C. S.; Chung, D. K.; Choi, H. S.; Biosci. Biotechnol. Biochem. 2001, 65, 2028.

23. Ohmiya, K.; Shimizu, M.; Taya, M.; Shimizu, S.; J. Bacteriol. 1982, $150,407$.

24. Huang, L.; Forsberg, C. W.; Appl. Environ. Microbiol. 1987, 53, 1034.

25. Castro, A. M.; Carvalho, M. L. A.; Leite, S. G. F.; Pereira Jr., N.; J. Ind Microbiol. Biotechnol., submetido.

26. Castro, A. M.; Dissertação de Mestrado, Universidade Federal do Rio de Janeiro, Brasil, 2006

27. Riou, C.; Salmon, J. M.; Vallier, M. J.; Günata, Z.; Barre, P.; Appl. Environ. Microbiol. 1998, 64, 3607.

28. Bollók, M.; Réczey, K.; Acta Aliment. 2000, $29,155$.

29. Shin, C. S.; Lee, J. P.; Lee, J. S.; Park, S. C.; Appl. Biochem.Biotechnol. 2000, 84-86, 237.

30. Aiello, C.; Ferrer, A.; Ledesma, A.; Bioresour. Technol. 1996, 57, 13.

31. Velkovska, S.; Marten, M. R.; Ollis, D. F.; J. Biotechnol. 1997, 54, 83.

32. Panagiotou, G.; Kekos, D.; Macris, B. J.; Cristakopoulos, B.; Ind. Crop. Prod. 2003, 18, 37.

33. Kalogeris, E.; Iniotaki, F.; Topakas, E.; Cristakopoulos, P.; Kekos, D.; Macris, B. J.; Bioresour. Technol. 2003, 86, 207.

34. Wen, Z.; Liao, W.; Chen, S.; Appl. Biochem. Biotechnol. 2005, 121-124, 93.

35. Jorgensen, H.; Morkeberg, A.; Krogh, K. B. R.; Olsson, L.; Enzyme Microb. Technol. 2005, 36, 42 .
36. Xia, L.; Cen, P.; Proc. Biochem. 1999, 34, 909.

37. Mo, H.; Zhang, X.; Li, Z.; Proc. Biochem. 2004, 39, 1293.

38. El-Nawwi, S. A.; El-Kader, A. A.; Biom. Bioen. 1996, 11, 361

39. Rajoka, M. I.; Malik, K. A.; Bioresour. Technol. 1997, 59, 21.

40. Zhang, C.; Xing, X. H.; Liu, M. S.; Biochem. Eng. J. 2004, 19, 181.

41. Kotchoni, O. S.; Shonukan, O. O.; Gachomo, W. E.; Afr. J.Biotechnol. 2003, 2, 140.

42. Juhász, T.; Egyházi, A.; Réczey, K.; Appl. Biochem. Biotechnol. 2005, $121-124,243$.

43. Li, X. L.; Dien, B. S.; Cotta, M. A.; Wu, Y. V.; Saha, B. C.; Appl. Biochem. Biotechnol. 2005, 121-124, 321.

44. Hayward, T. K.; Hamilton, J.; Tholudur, A.; McMillan, J.; Appl. Biochem. Biotechnol. 2000, 84-86, 859.

45. Massadeh, M. I.; Mohtar Wan Yussof, W.; Omar, O.; Kader, J.; Biotechnol. Lett. 2001, 23, 1771.

46. Gutierrez-Correa, M.; Tengerdy, R. P.; Biotechnol. Lett. 1997, 19, 665.

47. Juhász, T.; Szengyel, Z.; Szijártó, N.; Réczey, K.; Appl. Biochem. Biotechnol. 2004, 113-116, 201.

48. Liming, X.; Xueliang, S.; Bioresour. Technol. 2004, 91, 259.

49. Prasertsan, P.; H-Kittikul, A.; Kunghae, A.; Maneesri, J.; Oi, S.; World J. Microbiol. Biotechnol. 1997, 13, 555.

50. Sreenath, H. K.; Koegel, R. G.; Moldes, A. B.; Jeffries, T. W.; Straub, R. J.; Proc. Biochem. 2001, 36, 1199.

51. Teixeira, L. C.; Linden, J. C.; Schroeder, H. A.; Renew. Energ. 1999, 16, 1070.

52. Ballesteros, M.; Oliva, J. M.; Negro, M. J.; Manzanares, P.; Ballesteros, I.; Proc. Biochem. 2004, 39, 1843.

53. Kádár, Z.; Szengyel, Z.; Réczey, K.; Ind. Crop. Prod. 2004, 20, 103.

54. Miura, S.; Arimura, T.; Itoda, N.; Dwiarti, L.; Feng, J. B.; Bin, C. H.; Okabe, M.; J. Biosci. Bioeng. 2004, 97, 153.

55. Saha, B. C.; Iten, L. B.; Cotta, M. A.; Wu, Y. V.; Proc. Biochem. 2005, $40,3693$.

56. Tanaka, T.; Hoshina, M.; Tanabe, S.; Sakai, K.; Ohtsubo, S.; Taniguchi, M.; Bioresour. Technol. 2006, 97, 211.

57. Sharma, A.; Khare, S. K.; Gupta, M. N.; Bioresour. Technol. 2001, 78, 281.

58. Xiao, Z.; Zhang, X.; Gregg, D. J.; Saddler, J. N.; Appl. Biochem Biotechnol. 2004, 113-116, 1115

59. Pan, X.; Zhang, X.; Gregg, D. J.; Saddler, J. N.; Appl. Biochem. Biotechnol. 2004, 113-116, 1103.

60. Hang, Y. D.; Woodams, E. E.; Lebensm. Wiss. Technol. 2001, 34, 140.

61. Aguiar, C. L.; Menezes, T. J. B.; Biotecnologia Ciência \& Desenvolvimento 2002, 26, 52.

62. Carrillo, F.; Lis, M. J.; Colom, X.; Lopes-Mesas, M.; Valldeperas, J.; Proc. Biochem. 2005, 40, 3360.

63. Sendelius, J.; Dissertação de Mestrado, Lund University, Suécia, 2005.

64. Öhgren, K.; Rudolf, A.; Galbe, M.; Zacchi, G.; Biom. Bioen. 2006, 30, 863.

65. Tomás-Pejó, E.; García-Aparicio, M.; Negro, M. J.; Oliva, J. M.; Ballesteros, M.; Bioresour. Technol. 2009, 100, 890.

66. Imai, M.; Ikari, K.; Suzuki, I.; Biochem. Eng. J. 2004, 17, 79. 